\title{
The Place of Library Resources in Doctoral Programs
}

\begin{abstract}
This paper supplements an earlier paper by Robert B. Downs on doctoral programs and library resources. While the factors involved in successfully implementing a doctoral program are many and complex, to carry out such a program in a variety of fields, it appears that there should be at least three thousand current periodicals (and five hundred thousand volumes, as Dr. Downs states). Even with the best library resources, one cannot generally hope to produce more than one doctorate out of every ten graduate students enrolled in any year, as figures in this paper indicate.
\end{abstract}

I ms and Library Resources," R. B. Downs ${ }^{1}$ presented a table showing the number of doctoral degrees-minimum being five-conferred by all the educational institutions in the United States during the decade 1953-1962. The purpose of that paper was to consider if direct correlation exists between the number and variety of doctoral degrees awarded and the strength of library resources in individual institutions. One will easily agree with Dr. Downs that "since there are no established norms, exactly how many volumes should be held by the library and how much money spent for books in an institution offering doctoral programs are debatable matters. Pragmatically speaking, however, it seems doubtful that high level doctoral work in a variety of fields can be carried on with less than half a million volumes."

The purpose of the present paper is to consider briefly some of the other im-

1 "Doctoral Programs and Library Resources," CRL, XXVII (March 1966), 123-29.

Mrs. Subbarao is Catalog Librarian in the University of Alberta. portant factors upon which the production of doctoral degrees in an institution depends and the relative importance of library resources-books and current periodicals-as one of these factors. (Dr. Downs did not take into account the strength of current periodicals holdings as a factor, and his table does not give figures on this.) We also consider the proportion of doctorates conferred to the total number of graduate students enrolled.

It is a simple but important fact that the number of doctorates produced by an institution, or by one of its departments, depends almost entirely upon the number of graduate students who work for the doctorate degree. Also, if the concerned institution offers a doctoral program, the size of the doctoral student body has some, but by no means vital, relation to the size of the graduate student body as a whole. The number of admissions to the graduate school of an institution for a master's program depends upon various factors. As some of these, we might mention organization and admission policies, curricula, physical facilities, size of the undergraduate student body in the concerned institution and the other institutions in the 
neighborhood, the amount of better employment opportunities available in the surrounding community for higher qualified persons, financial aid available to graduate-level students, library resources, the size and stature of its faculty members, and the general reputation and standing of the institution in the academic world. Some of the abovementioned factors of course may have little or no relevance or importance in a specific institution. However, it would seem reasonable to assert that the last five of these factors have a direct bearing on the number of doctorates produced.

An institution may, as a part of its policy, emphasize its interest in and duty toward the advancement of knowledge and promotion of research. In pursurance of this policy, it may rapidly provide excellent physical facilities and even library resources. But it may still be unable to attract, even with the best of efforts, the right type of faculty members. This is the one thing that cannot be achieved as a crash program. But if it is successful over the years in securing a distinguished and widely recognized cadre of faculty members, the institution is indeed lucky, and it can be said to have crossed the main hurdle. Faculty members who devote a good deal of their time to research and writing will surely stimulate their graduate students with new and recent ideas. The presence of such a faculty in a department is doubtless the most important factor in determining the size of its doctoral students and the number of doctorates produced. Graduate students flock to such a department, for they know that they will be benefited and inspired by the presence of such a staff. From direct exchange of ideas they get the needed stimulus for creative scholarship, and at least some of the excitement of research going on in the department "rubs off" on the receptive minds of the students.
If the kind of faculty described above is available in a department which is offering a doctoral program, then the size of the library collection, even in the concerned departmental library, has really little relevance to the number of doctorates produced by the department. A good staff will surely see that the library collection pertaining to their field and to their discipline is adequate, and their doctorate production is bound to be good-not because of their library resources, but because of the quality of the staff (and students). A not-so-good staff in a department provided with sufficient financial resources can build up a vast library collection, but the production of doctorates may not be high. The existence of good library facilities is generally, at best, a necessary condition for the production of doctorates, but not at all a sufficient condition. In exceptional circumstances, this may not even be a necessary condition. This is because a thesis adviser may suggest research problems for which there is not much existing literature, or the student may gather all existing literature on a particular topic of research by means of reprints and preprints from the concerned authors, and then go on with his research with no more trips to the library! But, on the whole, one agrees with Dr. Downs that "an institution outstanding for its graduate offerings is almost invariably equally notable for the strength of its library resources." The converse, of course, is not true-and this could be for various reasons. A simple reason could be that the institution does not offer a graduate program at all, even though it might have outstanding faculty members-like the Institute for Advanced Study at Princeton. A second reason may be the lack of sufficient research oriented faculty members.

We might mention here a rather peculiar situation presented by some of the state colleges in the United States. Some have very decent library resources and 
a good number of research-minded faculty, but offer nothing beyond master's programs. Fortunately, such faculty put these resources to good use in connection with their own research work-even though they are not required to engage in research as a requisite for advance in salary or rank.

The table given in Dr. Downs's paper indeed provides some very curious facts. Harvard holds the first rank in the number of library volumes, but only fifth rank in the number of doctorates conferred, while the corresponding ranks for Columbia are sixth and first. (All these remarks pertain only to the decade 1953-1962, and the position could possibly have changed since then.) Wiscon-

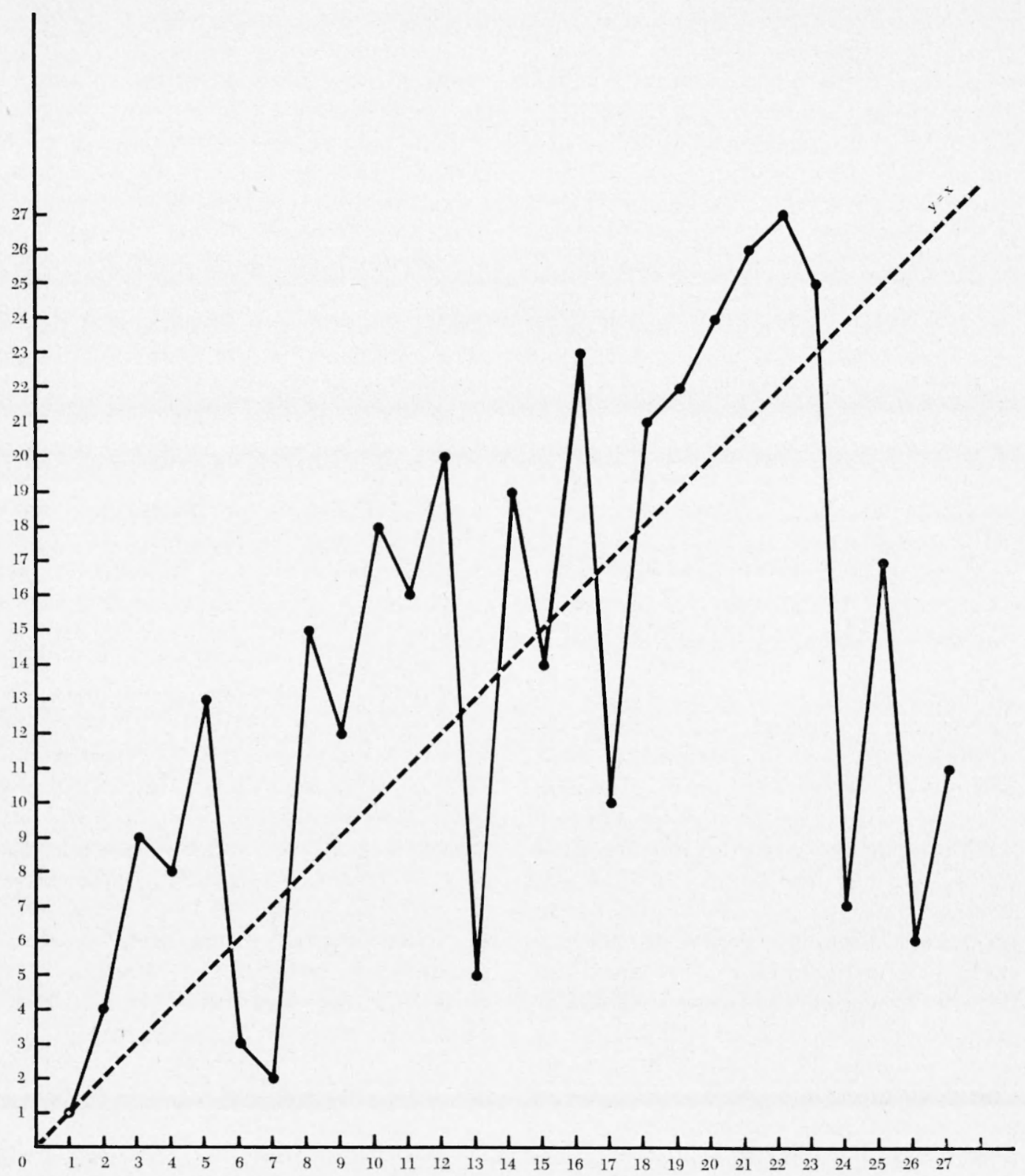

Fig. 1.-Correlation between number of doctorates conferred and number of volumes in institution's library, 1953-62. 
TABLE 1

\begin{tabular}{|c|c|c|c|c|c|c|}
\hline \multirow[b]{2}{*}{ INSTITUTION } & \multirow[b]{2}{*}{\begin{tabular}{c|} 
Rank of \\
Institution \\
in This Respect
\end{tabular}} & \multicolumn{2}{|c|}{$\begin{array}{l}\text { Doctora tes CoNFERED } \\
\text { IN } 1962-1963\end{array}$} & \multicolumn{2}{|c|}{$\begin{array}{l}\text { Graduate STUdents } \\
\text { EnRolLED 1962-63 }\end{array}$} & \multirow[b]{2}{*}{$\begin{array}{c}\text { CuRRENT } \\
\text { PERIODICALS }\end{array}$} \\
\hline & & No. & $\begin{array}{l}\text { Per Cent of All } \\
\text { Grad. Students }\end{array}$ & $\begin{array}{c}\text { Rank of } \\
\text { Institution } \\
\text { in This Respect }\end{array}$ & No. & \\
\hline $\begin{array}{l}\text { California } \\
\text { (all campuses) }\end{array}$ & 1 & 731 & 4 & 1 & 18,358 & 80,000 \\
\hline Columbia & 2 & 517 & 5 & 4 & 9,854 & $\begin{array}{c}\text { not } \\
\text { available }\end{array}$ \\
\hline Illinois & 3 & 450 & 6 & $\begin{array}{l}9 \\
8\end{array}$ & 7,115 & $\begin{array}{l}15,903 \\
, 5,883\end{array}$ \\
\hline Wisconsin & $\begin{array}{l}4 \\
5\end{array}$ & $\begin{array}{l}440 \\
428\end{array}$ & $\begin{array}{l}0 \\
9\end{array}$ & $\begin{array}{r}0 \\
13\end{array}$ & 4,862 & $\begin{array}{r}20,803 \\
9,076\end{array}$ \\
\hline Michigan & 6 & 370 & 4 & 3 & 10,412 & 21,290 \\
\hline N.Y.U. & 7 & 345 & 2 & 2 & 18,620 & 5,000 \\
\hline Ohio State & 8 & 329 & 8 & $1 \overline{5}$ & 4,373 & $16,200^{\circ}$ \\
\hline Minnesota & 9 & 314 & 6 & 12 & 5,647 & 12,432 \\
\hline Purdue & 10 & 290 & 7 & 18 & 3,871 & 11,682 \\
\hline Stanford & 11 & 276 & 6 & 16 & 4,340 & 26,096 \\
\hline M.I.T. & 12 & 274 & 9 & 20 & 3,142 & 3,215 \\
\hline Indiana & 13 & 266 & 3 & 5 & 8,969 & 12,000 \\
\hline Yale & 14 & 231 & 6 & 19 & 3,772 & $6,000 i$ \\
\hline Chicago & 15 & 227 & 5 & 14 & 4,779 & 55,000 \\
\hline Texas & 16 & 223 & 9 & 23 & 2,590 & 6,427 \\
\hline Mich. State & 17 & 223 & 3 & 10 & 6,587 & 13,173 \\
\hline Cornell & 18 & 206 & 7 & 21 & 3,102 & 13,361 \\
\hline Iowa & 19 & 205 & 8 & 22 & 2,721 & 6,750 \\
\hline Penn. State & 20 & 202 & 8 & 24 & 2,549 & 8,000 \\
\hline Iowa State & 21 & $17 \overline{4}$ & 11 & 26 & 1,662 & 9,470 \\
\hline Princeton & 22 & 171 & 18 & 27 & 956 & 16,000 \\
\hline Northwestern & 23 & 168 & 7 & 25 & 2,419 & $19,327 \ddagger$ \\
\hline Pennsylvania & 24 & 164 & 2 & 7 & 7,966 & 8,500 \\
\hline Univ. of Wash. & 25 & 161 & 4 & 17 & 4,317 & $17,300 \uparrow$ \\
\hline S. Calif. & 26 & 147 & 2 & 6 & 8,178 & 6,904 \\
\hline Pittsburgh & 27 & 138 & 2 & 11 & 5,661 & 9,534 \\
\hline
\end{tabular}

- Serials omitted.

† Some serials included.

¥ Some newspapers included.

sin holds third rank in the number of doctorates conferred, but only sixteenth in the number of library volumes held. Duke holds more library volumes than Wisconsin but takes only the thirty-seventh rank in the number of doctorates conferred. For every one hundred library volumes held by Purdue, Miami holds more than one hundred and nine volumes; but for each doctorate produced by Miami, Purdue produced 203 doctorates. Thus Purdue gets the thirteenth rank in this respect to Miami's 169 th! If there is a perfect correlation between the ranks by number of doctorates conferred and number of library volumes held, an institution holding a certain rank with respect to the former should hold the same rank with respect to the latter. Plotting the points corresponding to each of these institutions with these ranks taken, respectively, as the $\mathrm{x}$ and $\mathrm{y}$ coordinates, the resulting graph would, under a perfect correlation, be a straight line through the origin equally inclined to the $x$ and $y$ axes. The actual graph for the institutions which produced a minimum of a thousand doctorates during the decade under consideration is shown in Figure 1. The reader can see for himself how widely this graph differs from a perfect correlation, $\mathrm{y}=\mathrm{x}$.

What is the other available data then that may have relevance to the number of doctorates conferred by an institu- 


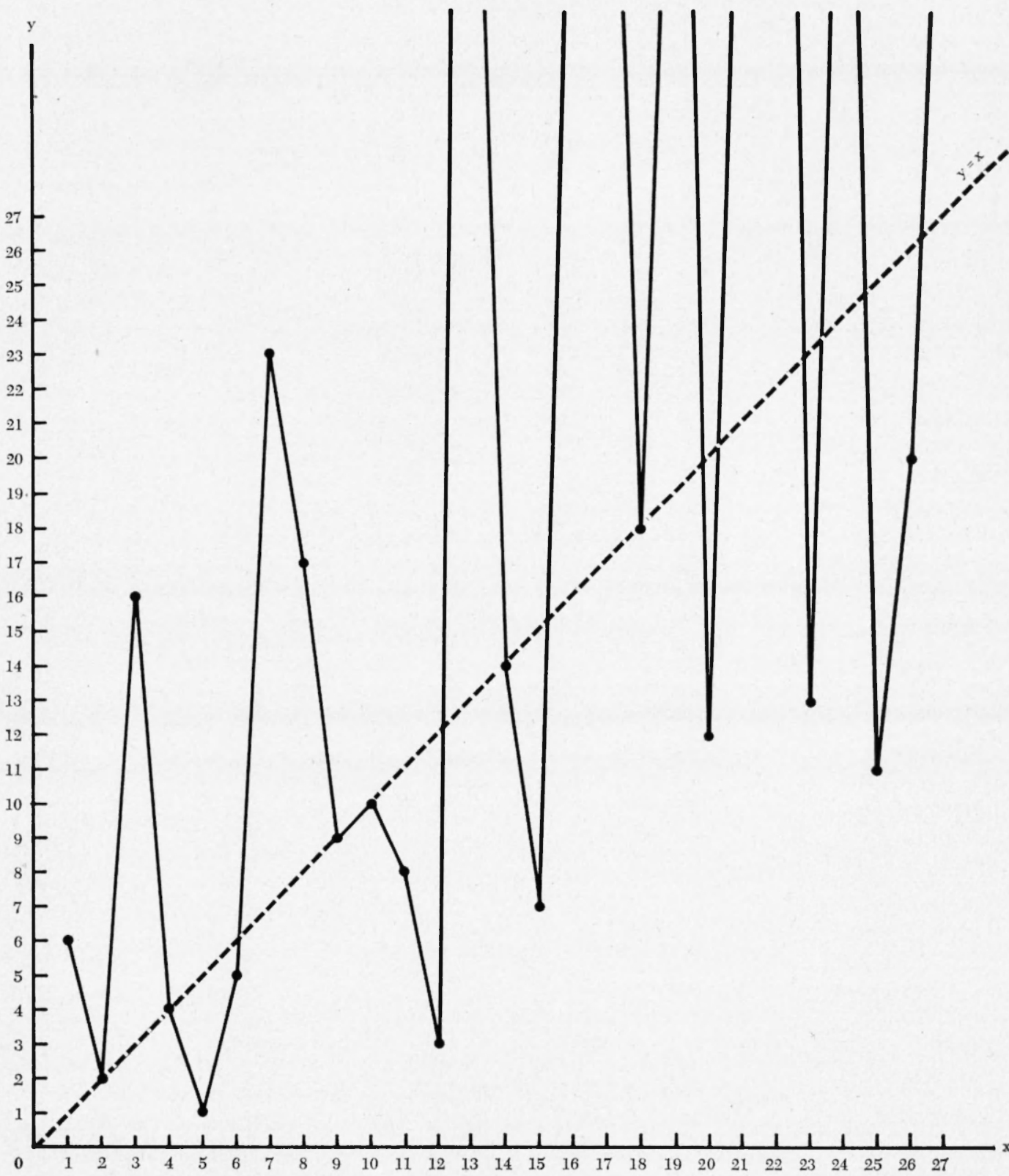

Fig. 2.-Correlation between number of doctorates conferred and number of graduate students enrolled, 1962-63.

tion? Since doctoral programs invariably involve writing a thesis, there should be, of course, facilities in the library for research, and this is certainly something indispensable. Since journals usually provide a greater source of current research material than do books, it is reasonable to consider if there is some correlation between the number of doctor- ates conferred and the number of current periodicals it receives. Another factor which may have a bearing, at least in the case of the big institutions, is the total number of graduate students enrolled in any year (both for master's and doctorates) in relation to the percentage of doctorates awarded.

Table 1 gives: (1) the total number of 
graduate students enrolled in the Fall of 1962 ; (2) the number of doctorates conferred during the period September 1962-June 1963; (3) the percentage these doctorates form out of the total number of these graduate students; and (4) the number of current periodicals in the concerned institution. This table is confined to the twenty-seven institutions which conferred at least a thousand doctorates during the decade 1953-1962. The table was prepared to determine if these data are helpful in drawing any significant conclusions, at least in the case of these leading institutions. Using the table, a graph (Fig. 2) was prepared that correlates the rank of the institution by virtue of number of doctorates conferred (plotted on the $\mathrm{x}$ coordinate) with its rank by virtue of number of graduate students enrolled during 1962-63 (plotted on the y coordinate). A similar graph using the total number of periodicals would have been useful; however, this could not be done since the figures available (as given in American Universities and Colleges, 1964 edition) sometimes include serials -either wholly or partly-and sometimes do not.

Table 1, like Dr. Downs's, shows some curious facts and gives some useful information. Except in very few cases, the number of doctorates conferred by an institution during 1962-1963 significantly exceeds the average number conferred for the same for the decade 19531962. This is doubtless to be expected with growing enrollments in the graduate schools, with larger numbers of research-minded faculty being appointed to the institutions, and with a growing emphasis on the importance of research degrees. Also, the first eight institutions in Dr. Downs's table are still the first eight in our table, though with small changes in their relative order. Wisconsin has fewer periodicals and fewer graduate students than Pittsburgh but has awarded more than three times the
TABLE 2

\begin{tabular}{|c|c|}
\hline $\begin{array}{l}\text { Doctorates con- } \\
\text { ferred, 1962- } \\
1963, \text { as per cent } \\
\text { of all graduate } \\
\text { students }\end{array}$ & $\begin{array}{llllllllll}18 & 11 & 9 & 8 & 7 & 6 & 5 & 4 & 3 & 2\end{array}$ \\
\hline No. of institutions & 1133352324 \\
\hline
\end{tabular}

number of PhD's and occupies in this respect the fifth rank to Pittsburgh's twenty-seventh. None of the institutions has fewer than three thousand current periodicals.

Turning to the percentage of graduate students who got doctoral degrees during the year under consideration, Princeton has the highest figure, 18 per cent, while having the lowest number of graduate students. The next highest is 11 per cent for Iowa State, and curiously this institution's graduate student enrollment is the second lowest. The lowest percentage is 2 , while the percentage held by the largest number of institutions is 6 . These details are summarized in Table 2 .

There may be many reasons for Princeton having the smallest enrollment of graduate students and yet producing the highest percentage of PhD's. As their graduate school Announcement says, their admissions are normally limited to male students, and the number of students in the graduate schools is strictly limited. With its excellent faculty and high reputation in the academic world, it will receive a large number of applicants, but, as their Announcement says, they choose the most outstanding among the applicants. There is no program at Princeton designed for students who wish to take the degree of Master of Arts as a terminal degree. The master's degree is granted there as an incidental degree, and is offered after completion of a portion of the requirements of the $\mathrm{PhD}$ degree. There are some other institutions which adopt roughly the same admission policies as Princeton, though the percentage of PhD's produced is not 
as high as that for Princeton. As an instance, we might mention Yale. Its Bulletin says that the size of each department is strictly controlled, and that, except for programs in industrial administration, international studies, and teaching, it gives preference in admission to candidates who intend to complete the $\mathrm{PhD}$ degree. It is of interest to notice that our table shows that Yale's percentage of PhD's out of a total graduate student body of 3,772 is only $6-$ which is a third of Princeton's. And Yale's faculty and academic standing are generally considered as good as anyone's. There may be a number of other factors involved which need to be considered. However, one can still draw some useful conclusions. Keeping aside Princeton and Iowa State as exceptions, the ratio of the number of PhD's conferred to the total number of graduate students enrolled is in all cases less than $1: 10$, and in more than half the cases it is even less than $1: 16$. This being the position in the top twenty-seven institutions, one can safely assume that things are no better in the cases of the other institutions.

In summary, we can say the following. To provide for an effective doctoral program and to hope to produce a decent number of PhD's annually, it would appear essential for an institution to have a book collection of at least half a million volumes (as Dr. Downs concluded); a periodicals collection (current subscriptions) of at least three thousand; and admissions policies which allow a graduate student body which is at least ten times the number of $\mathrm{PhD}$ 's it wishes to produce. But these, among many others, are only strictly necessary factors for successful implementation of doctoral programs. After a certain stage is attained, the number of library volumes held or the number of current periodicals becomes less and less significant as a factor in the number of doctorates produced. (The amount of money spent by the institution on improving its library resources is reflected by the number of books and current periodicals held, and it need not therefore be considered as a separate factor.) Again, merely trying to multiply the number of graduate students does not increase the output of $\mathrm{PhD}$ degrees. What matters most, after the above necessary conditions are met, are (1) the number of scholarly and research oriented faculty members who are active in publication and capable of inspiring and guiding the graduate students for doctoral work, and (2) the importance the institution's administrators assign to securing, retaining, and aiding such faculty. This of course depends in turn upon the financial resources of the institution, the availability of such qualified persons for recruitment, and various other factors which are beyond the scope of the present paper. If we had data (qualitative as well as quantitative) from each institution on the number of faculty members who are active in research, it would doubtless have provided a very significant factor in relation to the number of doctorates produced annually by the institution. One could only wish that such data were readily available.

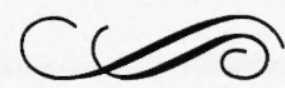

